\title{
The Use of Transition Region Characteristics to Improve the Numerical Simulation of Heat Transfer in Bypass Transitional Flows
}

\author{
FREDERICK F. SIMON \\ National Aeronautics and Space Administration, Lewis Research Center, Cleveland, Ohio 44135
}

\begin{abstract}
A method is presented for improving the numerical prediction of bypass transition heat transfer on a flat plate in a high-disturbance environment with zero or favorable pressure gradient. The method utilizes low Reynolds number k- $\varepsilon$ turbulence models in combination with the characteristic parameters of the transition region. The parameters representing the characteristics of the transition region used are the intermittency, transition length and turbulent spot properties. An analysis is made of the transition length in terms of turbulent spot variables. The nondimensional spot formation rate, required for the prediction of the transition length, is shown by the analysis to be a function of the spot spreading angle, the dimensionless spot velocity ratio and the dimensionless spot area ratio. The intermittency form of the $k-\varepsilon$ equations was derived from conditionally averaged equations which have been shown to be an improvement over global-time-averaged equations for the numerical calculation of the transition region. The numerical predictions are in general good agreement with the experimental data and indicate the potential use of the method in accelerating flows. Turbulence models of the k- $\varepsilon$ type are known to underpredict the transition length. The present work demonstrates how incorporating transition region characteristics improves the ability of two-equation turbulence models to simulate bypass transition for flat plates with potential application to turbine vanes and blades.
\end{abstract}

Key Words: Turbine heat transfer; Bypass transition; Intermittency; Transition length; Turbulent spot

\section{INTRODUCTION}

$\mathbf{T}$ The present effort is part of a program by the National Aeronautics and Space Administration (NASA) for the investigation of the heat transfer in the transition region of turbine vanes and blades.

The transition from laminar to turbulent boundary layer flow affects great increases in the local wall shear stress and heat transfer. This effect of transition is especially critical for airfoil surfaces such as turbine blades/vanes where 50 percent or more of the surface can be in transition. The ability to predict the onset and extent of transition is important to the determination of turbine blade heat transfer that critically affects durability and engine thermal performance. The accurate prediction of gas side shear stress and heat transfer on turbine blades will become more critical as the desired operating temperatures of advanced turbine engines increase. The present methods for predicting transition shear stress and heat transfer on turbine blades are based on incomplete knowledge. There is incomplete knowledge about the transition process in an engine environment where disturbance levels are initially large, although recent surveys (Mayle, 1991; and Volino and Simon, 1991) indicate much progress in this area. In these large disturbance environments traditional linear mechanisms are bypassed and finite nonlinear effects must be considered.

Full modeling of this transition phenomena for the purpose of predicting wall shear stress and heat transfer on turbine blades must consider the effects of free-stream turbulence, pressure gradient, streamwise curvature, surface roughness, wall/free-stream temperature ratio and flow disturbances (e.g., turbine blade wakes). The present work, a first step, concentrates on the effects of 
free-stream turbulence and pressure gradient on a flat plate. The objective is to demonstrate a modeling approach to the transition region that will improve the numerical prediction of that region.

Properly used, Low Reynolds Number k- $\varepsilon$ turbulence models for calculating the transition heat transfer in environments of high disturbance appear to simulate the onset of transition governed by the transport of turbulence energy from the free stream into the boundary layer. However, while two-equation turbulence models predict an acceptable value for transition onset, the resulting process is generally too abrupt, resulting in an underprediction of the transition length (e.g., Rodi and Scheuerer, 1985; and Simon, 1993). The experimental evidence (Volino and Simon, 1993) suggests that the physics of the transition region is characterized by an incomplete development of the cascade of energy from large to small scale turbulence and the k- $\varepsilon$ model does not completely account for this. Three modifications of the $\mathrm{k}-\varepsilon$ model, as a potential means of improving the simulation of transition physics, are reviewed by Simon (1993). The three methods are (1) the use of a multitime-scale k- $\varepsilon$ model (Crawford, 1992), (2) modification of the turbulent production term in the differential equation for the turbulent kinetic energy (Schmidt and Patankar, 1988), and (3) the use of intermittency in the k- $\varepsilon$ equations (Simon and Stephens, 1991).

Simon and Stephens combined the conditionally averaged momentum, energy, and turbulence equations for the turbulent spot and nonturbulent portion of the intermittent flow of the transition region to obtain global values of velocity and temperature. The resulting equations contain the additional variable of intermittency which requires knowledge of the transition length. A transition length estimate was made by Simon and Stephens (1991) using the method of Narasimha (1985). It expresses the transition length in terms of a nondimensional spot formation rate $(\mathrm{N})$ which is assumed to be constant for free-stream turbulence levels greater than about 1 percent. Simon and Stephens followed the approach of Narasimha and determined the value of $\mathrm{N}$ based on experimental data. This permitted a calculation of transition length in terms of the momentum Reynolds number for transition onset. The transition length may also be determined using an empirical approach (e.g., Dhawan and Narasimha, 1958; and Narasimha, 1978) or by the use of turbulent spot analyses (Walker and Gostelow, 1990; Walker, 1989; McCormick, 1968).

The present work follows the line of reasoning given in the latter analytical works to develop a model for the nondimensional spot formation rate $(\mathrm{N})$ for a prediction of transition length and intermittencies required for the equations of Simon and Stephens. The equation developed for predicting of the transition length is expressed in terms of turbulent spot characteristics of spreading angle, velocity, and physical dimensions. A check of the analytical formulation is made using the recent turbulent spot data of Clark, LaGraff, Magari, and Jones (1992).

Having a method to predict transition length and intermittency permits the prediction of transition heat transfer. In this work numerical predictions are made for transition heat transfer, using the modified Jones-Launder turbulence model of Simon and Stephens (1991) with the TEXSTAN boundary layer computer code (Crawford, 1985). The numerical predictions are compared with the flat plate, zero, and favorable pressure gradient data of Blair and Werle $(1980,1981)$.

\section{Transition Region Equations}

The beginning of the transition region is defined by the first appearance of turbulence spots. The transition region is characterized by the intermittent appearance of these turbulent spots, which grow as they move downstream until they finally merge to form the turbulent boundary layer. The transition region, therefore, may be described as having turbulent spots with laminar-like fluid surrounding the spots. Vancoille and Dick (1988) state that conventional turbulence models based on global time averages cannot give a good description of such intermittent flow, resulting in poor agreements for the turbulence intensity profiles for the boundary layer. They reported that using conditional averaging techniques for the turbulent spots and the laminar like fluid surrounding the spots resulted in a good prediction of the experimental values of the velocity profiles and the turbulence intensity profiles in the transition region. The work of Simon and Stephens (1991) extended the work of Vancoille and Dick (1988) to predicting heat transfer in the transition region. The conditioned momentum, energy and turbulence equations for the turbulent spots and nonturbulent portion ("laminar") of the intermittent flow in the transition region are combined and simplified to obtain global values of velocity and temperature. The present work refines the previous work of Simon and Stephens (1991) by removing the need to use an empirical nondimensional spot formation rate $(\mathrm{N})$ for prediction of transition length and by extending the prediction of $\mathrm{N}$ to include pressure gradient. A brief review of the key equations follow.

As shown by Simon and Stephens, when the modeled equations for the turbulent and laminar zones are combined and the assumption made of negligible Reynolds 
stresses in the "laminar" zone, the following momentum and energy equations are obtained:

$$
\begin{gathered}
\rho u \frac{\partial u}{\partial x}+\rho v \frac{\partial u}{\partial y}=\frac{\partial}{\partial y}\left[\mu \frac{\partial u}{\partial y}-\gamma \rho\left(\overline{u^{\prime} v^{\prime}}\right)\right]-\frac{d p}{d x} \\
\rho u \frac{\partial T}{\partial x}+\rho v \frac{\partial T}{\partial y}=\frac{\partial}{\partial y}\left[\lambda \frac{\partial T}{\partial y}-\gamma \rho\left(\overline{v^{\prime} T^{\prime}}\right)\right] \\
-\rho \overline{u^{\prime} v^{\prime}}=\mu_{t} \frac{\partial u}{\partial y}=\left(C_{\mu} f_{\mu} \rho k^{2} / \varepsilon\right) \frac{\partial u}{\partial y} \\
-\rho\left(\overline{v^{\prime} T^{\prime}}\right)=\frac{\mu_{t}}{P r_{t}} \frac{\partial T}{\partial y}
\end{gathered}
$$

The modified Jones-Launder (1973) turbulence model of Simon and Stephens (1991) is as follows:

$$
\begin{aligned}
& \rho u \frac{\partial k}{\partial x}+\rho v \frac{\partial k}{\partial y}=\frac{\partial}{\partial y}\left[\left(\mu+\gamma \frac{\mu_{t}}{\sigma_{k}}\right) \frac{\partial k}{\partial y}\right]+\gamma \mu_{t}\left(\frac{\partial u}{\partial y}\right)^{2} \\
& -\rho \gamma \varepsilon-2 \mu\left(\frac{\partial k^{1 / 2}}{\partial y}\right)^{2} \\
& \rho u \frac{\partial \varepsilon}{\partial x}+\rho v \frac{\partial \varepsilon}{\partial y}=\frac{\partial}{\partial y}\left[\left(\mu+\gamma \frac{\mu_{t}}{\sigma_{\varepsilon}}\right) \frac{\partial \varepsilon}{\partial y}\right]+C_{1} \frac{\varepsilon}{k} \gamma \mu_{t}\left(\frac{\partial u}{\partial y}\right)^{2} \\
& -\rho C_{2} f_{2} \gamma \frac{\varepsilon^{2}}{k}+2 \frac{\mu \gamma \mu_{t}}{\rho}\left(\frac{\partial^{2} u}{\partial y^{2}}\right)^{2}
\end{aligned}
$$

Equations (1) to (6) are the simplified equations for the transition region derived by Simon and Stephens (1991). Constants for the turbulence model are given in Table I. These equations require the specification of intermittency. Equation (1) shows the Reynolds stresses multiplied by the intermittency factor. This is the form utilized by McDonald and Fish (1973) and others.

TABLE I

Constants and Functions for Jones-Launder Turbulence Model

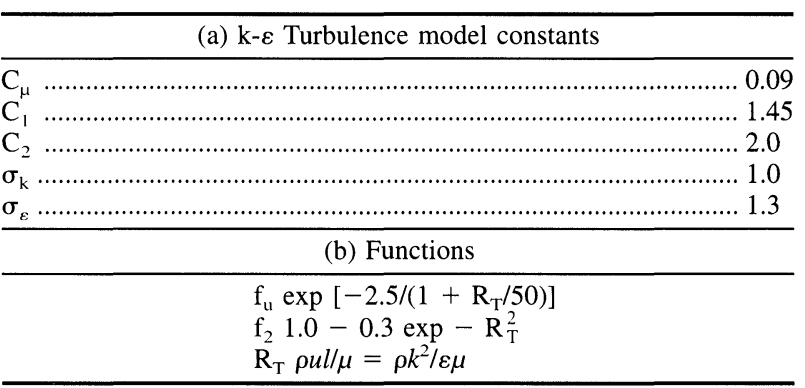

\section{Intermittency}

Specification of intermittency requires knowledge of the transition path in terms of transition start and of the transition length. Narasimha (1957), utilizing a concentrated breakdown hypothesis, derived the following transition path equation from the turbulent spot theory of Emmons (1951):

$$
\gamma=1-\exp \left[-4.61\left(\frac{x-x_{t r}}{L_{t r}}\right)^{2}\right] \text { for } \gamma=0 \rightarrow 0.99
$$

Equation (7) has been compared to experimental data and has been found to be valid. Figure 1, from Volino and Simon (1991), compares the experimental data from Kim (1991), Kuan and Wang (1990), Sohn, O'Brien, and Reshotko (1989), and Blair and Anderson (1987) with Eq. (7). Figure 1 is an example of the good agreement that has been found with experimental data and Eq. (7).

Using the approach of Narasimha (1985) the transition length may be expressed in terms of the transition Reynolds number and a nondimensional spot formation rate as follows:

$$
R e_{L_{t r}}=\frac{2.15}{\sqrt{N}} R e_{\theta_{r r}}^{3 / 2}
$$

Where $\mathrm{N}$, the nondimensional spot formation rate is defined as

$$
N=n \sigma \theta_{t r}^{3} / \nu
$$

In what follows an analysis is made of spot inception and growth. Spot inception is described in terms of the onset position and frequency of disturbance. The frequency of disturbance is taken to be the Tollmien-Schlichting wave

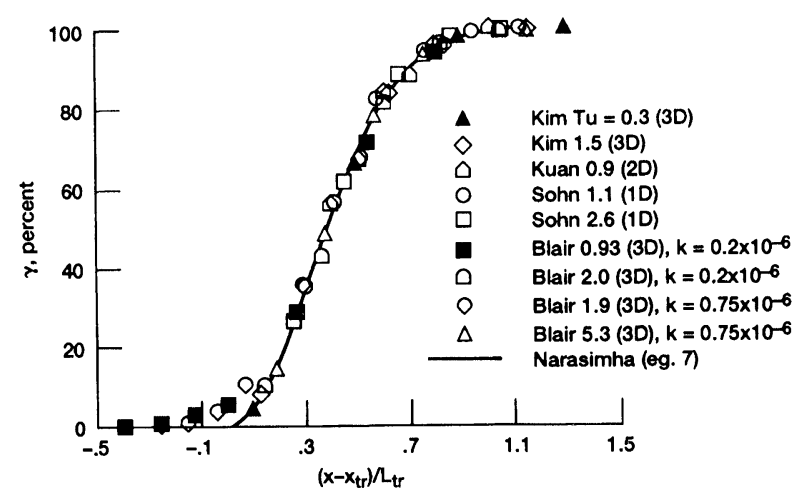

FIGURE 1 Intermittency (Volino and Simon, 1991). 
frequency having the maximum amplification. This permits an expression for the dimensionless spot formation rate $(\mathrm{N})$ in terms of the spot spreading angle, spot velocity, and spot physical dimensions. The transition length may then be calculated using Eq. (8).

\section{Spot Formation Rate (N) Analysis}

Chen and Thyson (1971) used the observations obtained from stability experiments with controlled disturbances, that prior to laminar flow breakdown the wave motions become three-dimensional with regularly spaced peaks and valleys. The initial breakdowns of laminar flow, occurring at the peaks, act as the initial stage for the development of turbulent spots. The turbulent spots grow and spread and eventually meet to form a fully developed (albeit immature) turbulent boundary layer. This process is illustrated in Fig. 2. The transition length, defined as the length from inception to the first meeting of adjacent spots, was shown by McCormick (1968) to be related to the distance between turbulent spots at onset (see Fig. 2) as follows:

$$
d=2 L_{t r} \tan \alpha
$$

From the following intermittency-path equation derived by Narasimha (1957)

$$
\gamma=1-\exp \left[-\frac{n \sigma}{U_{e}}\left(x-x_{t r}\right)^{2}\right]
$$

We obtain for $\gamma=0.99$ at $\mathrm{x}=\mathrm{x}_{\mathrm{E}}$

$$
L_{t r}=\left(4.61 \frac{U_{e}}{n \sigma}\right)^{1 / 2}
$$

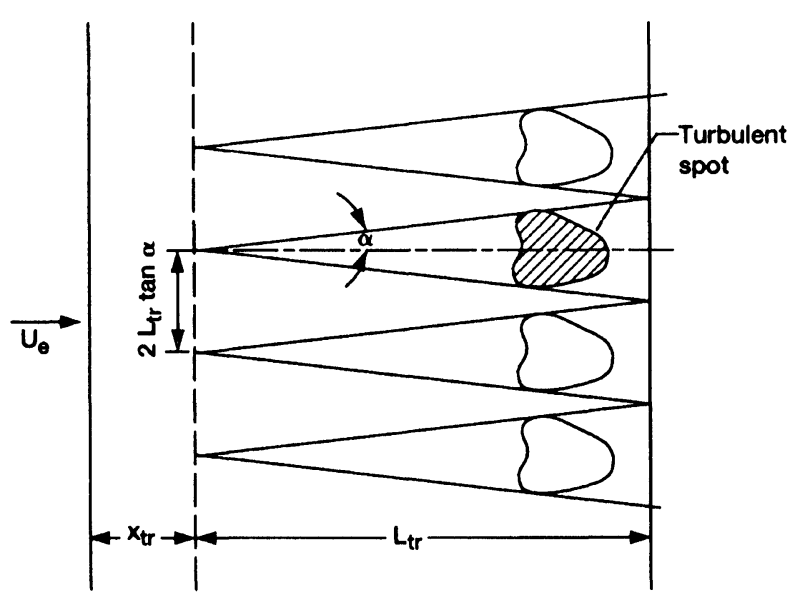

FIGURE 2 Turbulent spot inception/growth model.
Substituting Eq. (12) in Eq. (10) we obtain

$$
d=2\left(4.61 \frac{U_{e}}{n \sigma}\right)^{\frac{1}{2}} \tan \alpha
$$

Based on the assumption that breakdown to a turbulent spot occurs at the peak for each cycle of wave motion. Chen and Thyson (1971) state that the spot formation rate (n) can be related to the frequency of disturbance (f) and the spanwise wavelength. This is stated here in terms of the distance between onset of spots (d) as follows:

$$
n=f / d
$$

So that by combining Eqs. (13) and (14) we have

$$
n=\frac{f^{2} \sigma}{4 \tan ^{2} \alpha 4.61 U_{e}}
$$

The dimensionless spot formation rate as defined by Narasimha (1985) is given by Eq. (9), which can be reformulated and expressed as

$$
N=\frac{n \sigma v^{2}}{U_{e}^{3}} R e_{\theta_{t r}}^{3}
$$

Substituting Eq. (15) in to Eq. (16) we obtain

$$
N=\left(\frac{f \sigma v}{2 \tan \alpha U_{e}^{2}}\right)^{2} \frac{R e_{\theta_{t r}}^{3}}{4.61}
$$

According to Eq. (17) the dimensionless spot formation rate is a function of disturbance frequency, dimensionless spot propagation parameter, the turbulent spot spreading angle, the momentum Reynolds number for transition onset and the free-stream velocity. For the purpose of estimating $\mathrm{N}$, the frequency (f) of spot formation is determined using the method of Walker (1989). Walker applied the model of McCormick (1968) who assumed that turbulent spots appeared at the frequency of the basic Tollmien-Schlichting instability wave. He assumed that the dominant disturbance frequency at breakdown to be the TS wave frequency having the maximum amplification ratio according to the small-disturbance stability calculations, for a Falkner-Skan profile, obtained by Obremski et al. (1969). The equation for the locus of maximum amplification rates over the whole range of the Falkner-Skan pressure gradient parameter (including zero pressure gradient) as given by Walker is as follows:

$$
f=\frac{0.7676 U_{e}^{2}}{2 \pi \nu \operatorname{Re}_{\theta_{t r}}^{3 / 2}}
$$


Walker presents experimental evidence, for a free-stream turbulence of 0.3 percent, to justify employment of Eq. (18). Roach and Brierley (1992) also demonstrate the ability of Eq. (18) to predict maximum T-S frequencies for transition occurring at 1 percent free-stream turbulence and zero pressure gradient. Substitution of Eq. (18) in Eq. (17) results in the following

$$
N=8.1 \times 10^{-4}\left(\frac{\sigma}{\tan \alpha}\right)^{2}
$$

From Emmons (1951), the following expression for the dimensionless spot propagation parameter is obtained

$$
\sigma=\frac{\Lambda \tan ^{2} \alpha}{\beta}
$$

Where $\Lambda$ is a dimensionless parameter related to the physical dimensions of the spot and $\beta$ is a dimensionless spot velocity.

Substituting Eq. (20) in Eq. (19) the following equation for $\mathrm{N}$ is obtained

$$
N=\left(\frac{\Lambda \tan \alpha}{\beta}\right)^{2} 8.1 \times 10^{-4}
$$

Equation (21) for $\mathrm{N}$ is only a function of turbulent spot characteristics and appears to justify the use of a constant value for $\mathrm{N}$ as suggested by Narasimha (1985). Narasimha (1985) found that for freestream turbulence levels greater than 0.1 percent, at zero pressure gradient, the value of $\mathrm{N}$ has the approximate constant value of 0.7 $\times 10^{-3}$. However, using an $11^{\circ}$ spot spreading angle as determined by Schubauer and Klebanoff (1955), a value of $\Lambda=2$ as estimated by Emmons (1951) and a value of $\beta=0.65$ based on the work of Clark, Jones, Ashworth, and LaGraff (1991) results in a value of $\mathrm{N}=0.29 \times$ $10^{-3}$ from Eq. (21). According to Eq. (20) the value of $\sigma$ is 0.12. On the other hand, Narasimha (1985) reports a $\sigma$ value of 0.25 which, using Eq. (19), results in $\mathrm{N}=1.3 \times$ $10^{-3}$. Thus we can see that $\mathrm{N}$ is quite sensitive and there is a fair spread in its value. However, the calculation sensitivity is lower for the transition length since it is a function of the square root of $\mathrm{N}$ (Eq. (8)). Using the zero pressure gradient experimental data sets of Schbauer and Skramstad (1948), Abu-Ghannam and Shaw (1980), Sohn and Reshotko (1991), Suder, O'Brien, and Reshotko (1988), Kim (1991), and Eq. (8), values of $\mathrm{N}$ were calculated and are given in Fig. 3. In Fig. 3, the values of $\mathrm{N}$ determined from the experiments are compared to the above calculated values of $\mathrm{N}$ using Eqs. (19) and (21). As shown in Fig. 3 the calculated $\mathrm{N}$ values cover the range $\square$ Schbauer and Skramstad (1948)

O Abu-Ghannam and Shaw (1980)

$\diamond$ Sohn and Reshotko (1991)

D Suder, O'Brien and Reshotko (1988)

$\triangle \operatorname{Kim}(1991)$

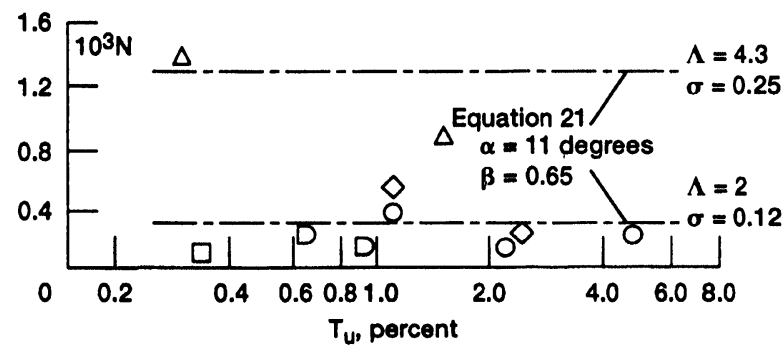

FIGURE 3 Variation of nondimensional spot formation rate with free-stream turbulence (Narasimha (1985) method) for zero pressure gradient.

of the experimental data, with a preference for the lower $\mathrm{N}$ value of $0.29 \times 10^{-3}$. In the above calculations for $\mathrm{N}$ at zero pressure gradient, a spreading angle of $11^{\circ}$ was assumed for the low Mach number conditions of the experiments. Clark, Jones, and LaGraff (1994) report that the spot spreading angle decreases monotonically with an increase in the Mach number. Their experimental data are shown in Fig. 4. Extrapolation of their data to the low Mach number conditions of the experiments of Fig. 3 indicates that the use of an $11^{\circ}$ spreading angle is justified.

The experimental turbulent spot data reported by Clark, LaGraff, Magari, and Jones (1992) can be used as an example of the utility of Eqs. (8) and (21) to calculate

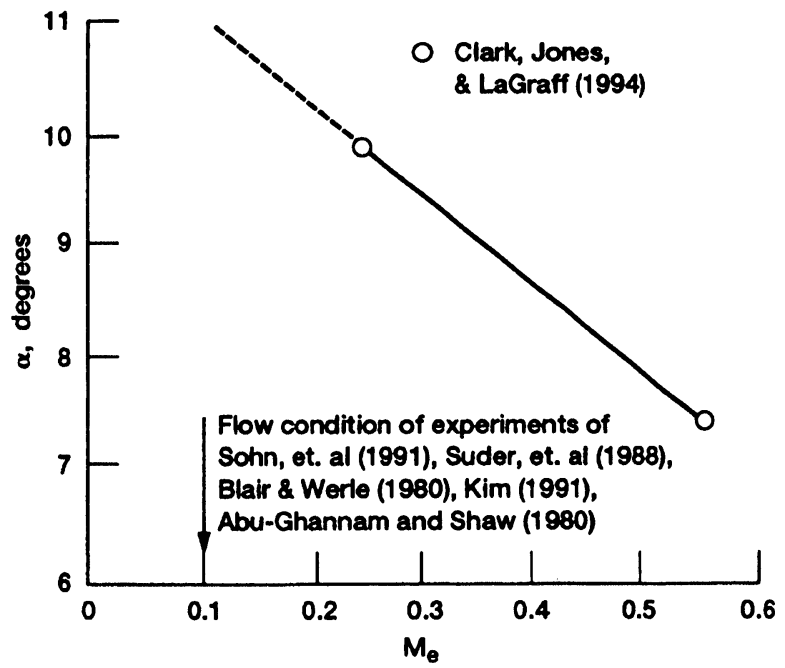

FIGURE 4 Variation of spot spreading angle $(\alpha)$ with free-stream Mach number $\left(\mathrm{M}_{\mathrm{e}}\right)$ for zero pressure gradient. 
the transition length. The experiments presented in this paper were performed at Oxford University in a 6-in. Isentropic Light Piston Tunnel. Measurements were made of naturally occurring turbulent spots with the use of surface thin-films heat transfer gauges. Assuming $\Lambda=$ 2 and $\beta=0.65$, calculations were made for the transition length and compared to experimental values obtained from intermittency plots presented in the above reference. The results are shown in Table II for a zero pressure gradient and a mild adverse pressure gradient. The comparisons between experiment and calculation in Table II are good and indicate that the method presented in this paper shows promise.

Utilizing the value of $\mathrm{N}=0.29 \times 10^{-3}$ obtained above in Eq. (8) results in the following equation for the calculation of the transition length for a zero pressure gradient:

$$
R e_{L_{t r}}=124 R e_{\theta_{t r}}^{3 / 2} \text { for } \gamma=0 \rightarrow 0.99
$$

Wyganaski (1981) reports a turbulent spot spreading angle of $5^{\circ}$ for a favorable pressure gradient. The transition length equation, based on a $5^{\circ}$ spreading angle, for a favorable pressure gradient with a $\mathrm{k}=0.75 \times 10^{-6}$ assuming the same $\Lambda$ value used in the zero pressure gradient case and a $\beta=0.8$ reported by Wyganaski, is as follows:

$$
R e_{L_{\alpha}}=344 R e_{\theta_{\alpha}}^{3 / 2} \text { for } k=0.75 \times 10^{-6}
$$

Equations (22) and (23) may be graphically represented in the manner suggested by Dhawan and Narashima (1958). This is done in Fig. 5 for a number of experimental data sets given in a survey report by Volino and Simon (1991). Figure 5, for the cases of flow acceleration, uses the average velocity between transition onset and end for calculating the Reynolds number for the transition length (ordinate of Fig. 5). In general, there is

TABLE II

Comparison of Calculated Transition Length with the Experimental Data of Clark, LaGraff, Magar., and Jones (1992)

\begin{tabular}{lcccc}
\hline $\begin{array}{l}\text { Pressure } \\
\text { gradient }\end{array}$ & $\begin{array}{c}\alpha, \\
\text { Experimental }\end{array}$ & $\begin{array}{c}\mathrm{N}, \\
\text { Eq. }(21)\end{array}$ & \multicolumn{2}{c}{$\mathrm{L}_{\mathrm{tr}}(\mathrm{ft})$} \\
\hline & & & $\begin{array}{c}\text { Calculated } \\
\text { Eq. (8) }\end{array}$ & Experimental \\
\cline { 3 - 4 } $\begin{array}{c}\text { Zero, } \\
\mathrm{M}_{\mathrm{e}}=0.55\end{array}$ & $7.6^{\circ}$ & $\begin{array}{c}0.137 \times \\
10^{-3}\end{array}$ & 0.28 & 0.20 \\
Mild adverse & $15^{\circ}$ & $0.55 \times 10^{-3}$ & 0.14 & 0.16 \\
\hline
\end{tabular}

good agreement of Eqs. (22) and (23) with the experimental data. From the pressure gradient conditions reported by Wyganaski (1981), a value of $\mathrm{k}=0.63 \times 10^{-6}$ was calculated at onset for the Blair and Anderson (1987) experiment $\left(\mathrm{k}=0.75 \times 10^{-6}\right)$. This helps to justify the use of a $5^{\circ}$ spreading angle for obtaining Eq. (23). Figure 5 demonstrates that with an increase in flow acceleration there is an increase in transition length and that this increase in transition length is consistent with the characteristics of turbulent spots under accelerating conditions. The above is not considered to be a definitive test for the use of Eq. (21), but points to the need for a further study of turbulent spots subject to conditions of pressure gradient.

\section{Heat Transfer Calculations}

A calculation of the transition region was made utilizing Eqs. (1) to (7) and Eqs. (22) and (23) for estimating the transition length. These equations were numerically solved by using the TEXSTAN boundary layer computer code (Crawford, 1985). TEXSTAN is based on the STAN5 boundary layer program developed by Crawford and Kays (1976). The finite difference scheme of TEXSTAN is based on the numerical algorithm by Patankar and Spalding (1970). TEXSTAN solves the steady two-dimensional parabolic differential equations that govern boundary layer flow. This program sequentially solves the momentum equation and any number of transport equations such as stagnation enthalpy, turbulent kinetic energy (TKE), turbulent dissipation rate (TDR), and mass concentration governing

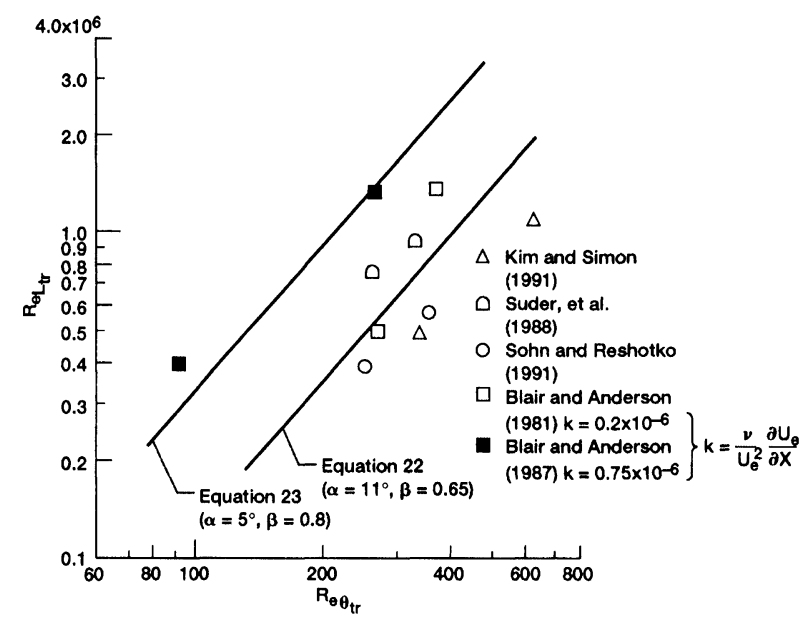

FIGURE 5 Transition length correlation 
equations. A calculation for the intermittency was initiated at transition onset. Transition onset was determined by the numerical method employed by Simon and Stephens (1991). This was assumed to occur when the boundary layer calculations prior to the use of intermittency showed a rapid increase in turbulence kinetic energy with a resulting increase in skin friction. Predicted onset values are compared, in Table III, to the experimental correlations of Abu-Ghannam and Shaw (1980) and Mayle (1991). Mayle's correlation does not account for pressure gradient; however, the effect of pressure gradient is small for a $\mathrm{k}$ of $0.75 \times 10^{-6}$. In general, there is a good comparison between the predicted and experimental transition onset values.

The following initial and boundary conditions were used in the numerical calculations.

\section{Initial and Boundary Conditions}

Wall boundary condition. Along the wall the no-slip boundary condition was applied.

$$
y=0: u=v=0
$$

For the energy equation a wall heat flux was prescribed.

$$
q_{w}=-K \frac{\partial T}{\partial y}(y=0)
$$

The turbulence kinetic energy and dissipation rate are set to zero at the wall.

$$
y=0: k=\epsilon=0
$$

The zero boundary condition for the dissipation was made possible by Jones and Launder (1973) by including additional terms in the turbulence energy (Eq. (5)).

TABLE III

\begin{tabular}{|c|c|c|c|c|}
\hline \multirow{3}{*}{$\begin{array}{c}\mathrm{T}_{\mathrm{u}}, \\
\text { percent }\end{array}$} & \multirow{3}{*}{$\begin{array}{l}\text { Pressure } \\
\text { gradient }\end{array}$} & \multicolumn{3}{|c|}{$\operatorname{Re}_{\theta_{\mathrm{tr}}}$} \\
\hline & & \multirow{2}{*}{$\begin{array}{c}\text { Predicted } \\
\text { Method of } \\
\text { Simon and } \\
\text { Stephens, } \\
1991\end{array}$} & \multicolumn{2}{|c|}{ Experimental correlations } \\
\hline & & & $\begin{array}{c}\text { Abu-Ghannam } \\
\text { and Shaw, } \\
1980\end{array}$ & $\begin{array}{c}\text { Mayle, } \\
1991\end{array}$ \\
\hline 1.4 & Zero & 356 & 410 & 324 \\
\hline 2.8 & Zero & 236 & 210 & 224 \\
\hline 2.2 & $\mathrm{k}=0.75 \times 10^{-6}$ & 244 & 282 & 244 \\
\hline
\end{tabular}

Comparison of Predicted Transition Momentum Thickness Reynolds Numbers with Experimental Correlations
Freestream boundary conditions. The freestream conditions may be expressed as a set of coupled ordinary differential equations as follows:

$$
\begin{gathered}
U_{e} \frac{d k_{e}}{d x}=-\varepsilon_{e} \\
U_{e} \frac{d \varepsilon}{d x}=-C_{2} \frac{\varepsilon_{e}^{2}}{k_{e}}
\end{gathered}
$$

Where initial values of the free-stream turbulence kinetic energy are determined from the turbulence intensity as follows:

$$
k_{e}=1.5\left(T u_{e} U_{e}\right)^{2}
$$

where

$$
T u_{e}=\frac{\sqrt{1 / 3\left(\overline{u^{\prime 2}}+\overline{v^{\prime 2}}+\overline{w^{\prime 2}}\right)}}{U_{e}}
$$

And the initial dissipation rate determined from the following:

$$
\varepsilon_{e}=k_{e}^{3 / 2} / L_{e}
$$

The dissipation length scale (Le) can be calculated from the longitudinal integral length scale using the method of Hancock (1980).

Initial values. To initiate calculations, a Blasius velocity profile and a flat temperature profile (unheated start) were utilized. For the turbulence transport equations the following initial profiles suggested by Rodi and Scheuerer (1985) were used:

$$
k=k_{e}\left(u / U_{e}\right)^{2}
$$

And

$$
\varepsilon=0.35 k \frac{\partial u}{\partial y}
$$

\section{RESULTS AND DISCUSSION}

Calculations are presented for turbulence levels of 1.4 and 2.8 percent at zero pressure gradient and 2.2 percent for a favorable pressure gradient with an acceleration parameter $(\mathrm{k})$ of $0.75 \times 10^{-6}$. It was necessary, to achieve good numerical results, to use about 100 grid points in the cross-stream directions. Comparisons of the calculations were made with the experimental data of 
TABLE IV

Boundary Conditions for Blair-Werle Data

\begin{tabular}{lccr}
\hline Parameter & Grid 1 & Grid 2 & $\begin{array}{r}\mathrm{k}=0.75 \times \\
10^{-6} \mathrm{Grid} 2\end{array}$ \\
\hline $\begin{array}{l}\text { Free-stream velocity, } \mathrm{U}_{\mathrm{e}}, \\
\mathrm{ft} / \mathrm{s}\end{array}$ & 100.0 & 100.0 & $32.6(\mathrm{x}=0)$ \\
$\begin{array}{l}\text { Free-stream temperature, } \\
\mathrm{T}_{\mathrm{e}},{ }^{\circ} \mathrm{F}\end{array}$ & 68.5 & 68.5 & 68.5 \\
$\begin{array}{l}\text { Wall heat flux, } \mathrm{q}_{\mathrm{w}} . \mathrm{Btu} / \\
\mathrm{ft}^{2} / \mathrm{s}\end{array}$ & 0.078 & 0.078 & 0.078 \\
$\begin{array}{l}\text { Free-stream turbulence } \\
\text { intensity, } \mathrm{Tu}_{\mathrm{e}}, \text { percent }\end{array}$ & 1.4 & 2.8 & \\
$\begin{array}{l}\text { Free-stream turbulence } \\
\text { kinetic energy, } \mathrm{k}_{\mathrm{e}}, \mathrm{ft}^{2} / \mathrm{s}^{2}\end{array}$ & 2.94 & 11.8 & 0.79 \\
$\begin{array}{l}\text { Free-stream dissipation } \\
\text { rate, } \varepsilon_{\mathrm{e}}, \mathrm{ft}^{2} / \mathrm{s}^{2}\end{array}$ & 127 & 511 & 1.51 \\
\hline
\end{tabular}

Blair and Werle $(1980,1981)$. These experiments were conducted in a low speed wind tunnel $(30 \mathrm{ft} / \mathrm{sec}$ to 130 $\mathrm{ft} / \mathrm{sec}$ ) under ambient air conditions utilizing grids for turbulence generation. A favorable pressure gradient was produced by the use of wedge in the test section. The test section was heated at a rate of $0.078 \mathrm{Btu} / \mathrm{ft}^{2}-\mathrm{sec}$ with an unheated length of $0.141 \mathrm{ft}$. The experimental boundary conditions used in the calculations are listed in Table IV.

The resulting calculations using Eqs. (1) to (6) are compared to Blair and Werle's experimental data in Figs. 6 to 8. Figure 6(a) is an example of the abrupt onset of transition that was obtained when intermittency was not used. The value of using intermittency is clearly demonstrated in Fig. 6(b). There is generally good agreement between experiment and prediction. Note in Fig. 7 that even after spot formation begins (transition onset) the boundary layer acts as if it were a laminar boundary layer up to intermittency values of 0.40 (1.4-percent case) and 0.49 (2.8-percent case). This is consistent with the measured velocity profiles of Sohn, Reshotko, and O'Brien (1989) which showed a Blasius profile for the laminar zone and a laminar like profile for the overall
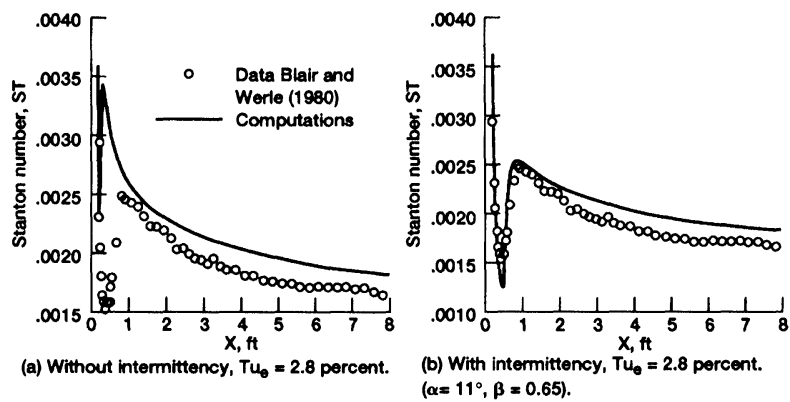

FIGURE 6 Use of intermittency to model transition region.

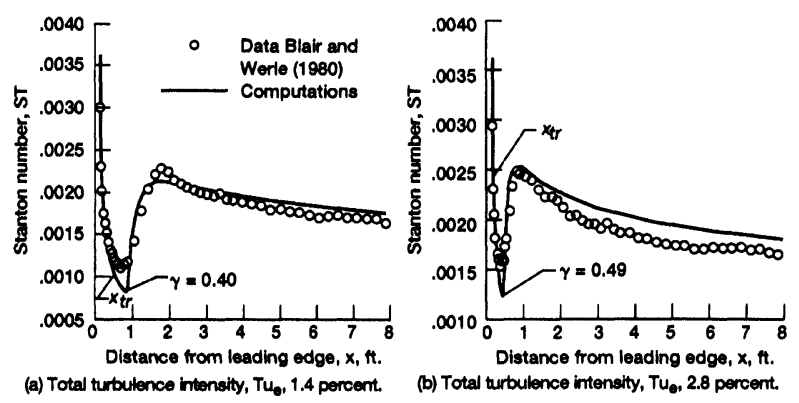

FIGURE 7 Comparison of prediction with experiment (zero pressure gradient, $\alpha=11^{\circ}, \beta=0.65$ ).

profile, for intermittency values up to 0.34 with a 1-percent free-stream turbulence. The numerical calculations capture the position of the minimum heat transfer. This is also true in the case with pressure gradient (Fig. 8). Figure 8 shows that, for the case of pressure gradient, there is general agreement between experiment and prediction, although the computed curve appears abrupt in the region of the minimum heat transfer. There is clearly a need to improve the model.

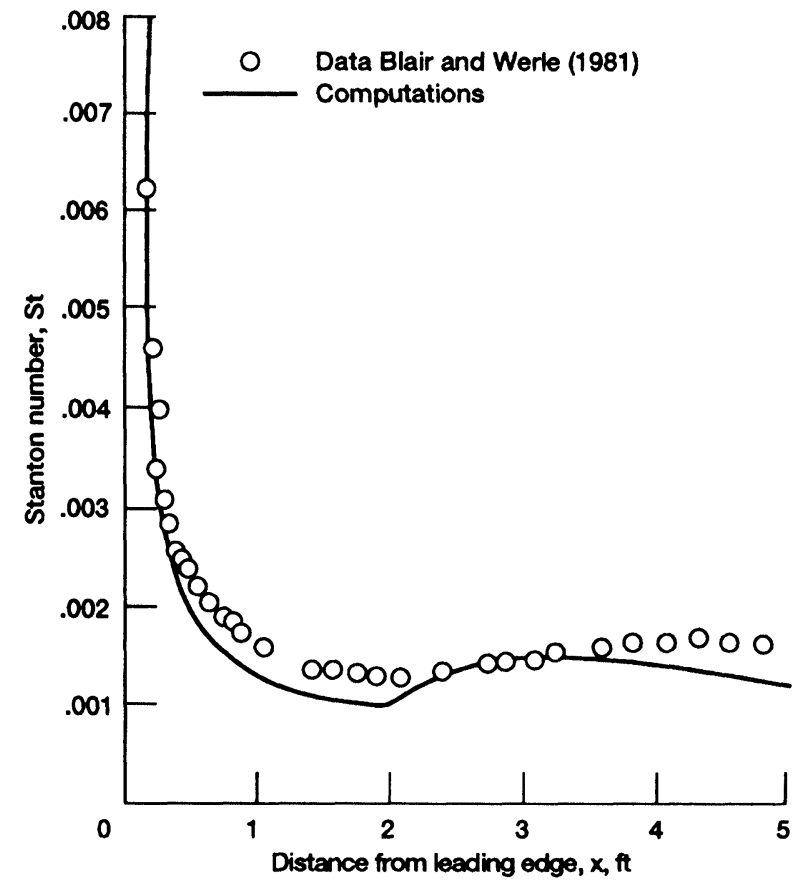

FIGURE 8 Comparison of prediction with experiment (favorable pressure gradient, $\mathrm{k}=0.75 \times 10^{-6}, \alpha=5^{\circ}, \beta=0.8$ ). Total turbulence intensity, $\mathrm{Tu}_{\mathrm{e}}, 2.2$ percent. 


\section{CONCLUDING REMARKS}

A demonstration has been made of the important role played by incorporating the characteristics of the transition region to provide improved modeling for predictive codes. A model has been developed for predicting the nondimensional spot formation rate $(\mathrm{N})$ in terms of turbulent spot variables. This model allows for a determination of the transition length and intermittency in terms of the turbulent spot velocity, turbulent spot spreading angle, and the turbulent spot physical dimensions. The model produced values of $\mathrm{N}$ which are in acceptable agreement with the values obtained from zero pressure gradient experiments. There is a need to further confirm the present approach by investigating the behavior of turbulent spots under conditions of pressure gradient and curvature for a determination of their relationship to transition length and intermittency. It is expected that the above information will aid the transition modeling efforts for the improved prediction of shear stress and heat transfer on turbine blades.

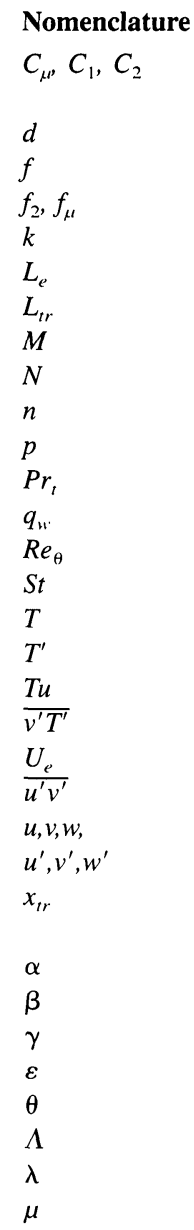

constants appearing in the $\mathrm{k}-\varepsilon$ turbulence model

distance between spots at onset disturbance frequency

low Reynolds number functions

turbulence kinetic energy

dissipation length scale

transition length

Mach number

nondimensional spot formation rate

spot formation rate

static pressure

turbulent Prandtl number

wall heat flux

momentum thickness Reynolds number

Stanton number

temperature

fluctuating temperature

turbulence intensity at free-stream

turbulent heat flux

free-stream velocity

turbulent shear stress

mean velocity in $\mathrm{x}, \mathrm{y}, \mathrm{z}$ directions

fluctuating velocities in $\mathrm{x}, \mathrm{y}, \mathrm{z}$ directions

location of transition onset (spot formation

begins)

spreading angle of spot

velocity of center of spot/free-stream velocity intermittency

dissipation rate

boundary layer momentum thickness

area of spot/square of half width

thermal conductivity/specific heat

molecular viscosity

$\begin{array}{ll}\mu_{t} & \text { eddy or turbulent viscosity } \\ v & \text { kinematic viscosity } \\ \rho & \text { fluid density } \\ \sigma & \text { dimensionless spot propagation parameter } \\ \sigma_{k}, \sigma_{\varepsilon} & \text { empirical constants in turbulence model }\end{array}$

\section{Subscripts}

$e$

tr

E

\begin{abstract}
free-stream value
transition onset
\end{abstract}

transition end

\section{References}

Abu-Ghannam, B.J. and Shaw, R. 1980. Natural Transition of Boundary Layers-The Effects of Turbulence, Pressure Gradient, and Flow History, Journal of Mech. Engr. Sci., Vol. 22, No. 5, pp. 213-228.

Blair, M.F. and Anderson, O.L. 1987. Study of the Structure of Turbulence in Accelerating Transitional Boundary Layers, United Technologies Research Center report R87-956900-1.

Blair, M.F. and Werle, M.J. 1980. The Influence of Free-Stream Turbulence on the Zero Pressure Gradient Fully Turbulent Boundary Layer, UTRC report R80-914388-12.

Blair, M.F. and Werle, M.J. 1981. Combined Influence of Free-Stream Turbulence and Favorable Pressure Gradients on Boundary Layer Transition, UTRC Report R81-914388-17.

Chen, K.K. and Thyson, N.A. 1971. Extension of Emmons' Spot Theory to Flows on Blunt Bodies, AIAA Journal, vol. 9, no. 5, pp. 821-825.

Clark, J.P., Jones, T.V., Ashworth, D.A., and LaGraff, J.E. 1991. Turbulent Spot Development in a Mach 0.55 Flow, ConferenceBoundary Layer Transition and Control, Organized by the Royal Aeronautical Society, Peterhouse College, Cambridge UK, Apr. 8-12.

Clark, J.P., LaGraff, J.E., Magari, P.J., and Jones, T.V. 1992. Measurement of Turbulent Spots and Intermittency Modelling at Gas-Turbine Conditions, Proceedings of the 80th NATO/AGARD PEP Symposium, Antalya, Turkey.

Clark, J.P., Jones, T.V., and LaGraff, J.E. 1994. On the Propagation of Naturally-Occurring Turbulent Spots, Journal of Engineering Mechanics on Turbulent Spots, ed. F.T. Smith.

Crawford, M.E. and Kays, W.M. 1976. STAN5-A program for Numerical Computation of Two-Dimensional Internal and External Boundary Layer Flows. NASA CR-2742.

Crawford, M.E. 1985. TEXSTAN program, University of Texas at Austin.

Crawford, M.E. 1992. Progress Report, NASA Grant NAG3-864.

Dhawan, S. and Narasimha, R. 1958. Some Properties of Boundary Layer Flow During the Transition from Laminar to Turbulent Motion. J. of Fluid Mech., vol. 3, pp. 418-436.

Emmons, H.W. 1951. The laminar-Turbulent Transition in a Boundary Layer-Part I.J. Aero Sciences 18, pp. 490-498.

Hancock, P.E. 1980. Effect of Free-Stream Turbulence on Turbulent Boundary Layers. Ph.D. Thesis, Imperial College, London University.

Jones, W.P. and Launder, B.E. 1973. The calculation of Low-Reynolds Number Phenomena With a Two Equation Model of Turbulence. Int. J. Heat Mass Transfer, vol. 16, pp. 1119-1130.

Kim, J. and Simon, T.W. 1991. Free-Stream Turbulence and Concave Curvature Effects on Heated, Transitional Boundary Layers, NASA CR-187150.

Kuan, C.L. and Wang, T. 1990. Investigation of the Intermittent Behavior of Transitional Boundary Layer Using a Conditional 
Averaging Technique, Experimental Thermal and Fluid Science, Vol. 3, pp. 157-173.

Mayle, R.E. 1991. The Role of Laminar-Turbulent Transition in Gas Turbine Engines, ASME paper 91-GT-261.

McCormick, M.E. 1968. An Analysis of the Formation of Turbulent Patches in the Transition Boundary Layer, ASME Journal of Applied Mechanics, vol. 35, pp. 216-219.

McDonald, H. and Fish, R.W. 1973. Practical Calculations of Transitional Boundary Layers. Int. J. Heat Mass Transfer, vol. 16, pp 1729-1744.

Narasimha, R. 1957. On the Distribution of Intermittency in the Transition Region of a Boundary Layer, J. Aeronautical Science, vol. 24, no. 9, pp. 711-712

Narasimha, R. 1978. A Note on Certain Turbulent Spot and Burst Frequencies, Report 78FM10, Dept. Aero. Eng., Indiana Institute of Science.

Narasimha, R. 1985. The Laminar-Turbulent Transition Zone in the Boundary Layer. Progress in Aerospace Science, vol. 22, pp. 29-80.

Obremski, H.J., Morkovin, M.V., and Landahl, M. 1969. A Portfolio of Stability Characteristics of Incompressible Boundary Layers, AGARDograph 134.

Patankar, S.V. and Spalding, D.B. 1970. Heat and Mass Transfer in Boundary Layers-A General Calculation Procedure. 2nd ed. Interext Books, London.

Roach, P.E. and Brierley, D.H. 1992. The Influence of a Turbulent Free-Stream on Zero Pressure Gradient Transitional Boundary Layer Development Part I: Test Cases T3A and T3B, Numerical Simulation of Unsteady Flows and Transition to Turbulence, Pironneau, et al. eds., Cambridge University Press, pp. 319-341.

Rodi, W. and Scheurer, G. 1985. Calculation of Laminar-Turbulen Boundary Layer Transition on Turbine Blades Proc. 65th AGARD PEP Symp. on Heat Transfer and Cooling in Gas Turbines, Bergen, Norway, May 6-10.

Schubauer, G.B. and Klebanoff, P.S. 1955. Contributions on the Mechanics of Boundary Layer Transition, NACA TN-3489.

Schubauer, G.B. and Skramstad, H.K. 1948. Laminar-Boundary Layer Oscillations and Transition on a Flat Plate, NASA Report 909.

Schmidt, R.C. and Patankar, S.V. 1988. Two-Equation Low-Reynolds-
Number Turbulence Modeling of Transitional Boundary Layer Flows. NASA CR-4145, May.

Simon, F.F. 1993. A Research Program for Improving Heat Transfer Prediction for the Laminar to Turbulent Transition Region of Turbine Vanes/Blades, NASA TM-106278.

Simon, F.F. and Stephens, C.A. 1991. Modeling of the Heat Transfer in Bypass Transitional Boundary-Layer Flows, NASA TP-3170.

Sohn, K-H., Reshotko, E., and O'Brien, J.E. 1989. Some Characteristics of Bypass Transition in a Heated Boundary Layer, Seventh Symposium on Turbulent Shear Flows, Vol. 1, Pennsylvania State University, pp. 2.4.1-2.4.6.

Sohn, K-H., O'Brien, J.E., and Reshotko, E. 1989. Some Characteristics of Bypass Transition in a Heated Boundary Layer, NASA TM-102126.

Sohn, K.H. and Reshotko, E. 1991. Experimental Study of Boundary Layer Transition With Elevated Freestream Turbulence on a Heated Flat Plate, NASA CR-187068.

Suder, K.L., O’Brien, J.E., and Reshotko, E. 1988. Experimental Study of Bypass Transition in a Boundary Layer, NASA TM-100913.

Vancoillie, G. and Dick, E. 1988. A Turbulence Model for the Numerical Simulation of the Transition Zone in a Boundary Layer, Int. J. Eng. Fluid Mech., vol. 1, no. 1.

Volino, R.J. and Simon, T.W. 1991. Bypass Transition in Boundary Layers Including Curvature and Favorable Pressure Gradient Effects, NASA CR-187187.

Volino, R.J. and Simon, T.W. 1993. An Application of Octant Analysis to Turbulent and Transitional Flow Data, Presented at the International Symposium on Gas Turbines in Cogeneration, IGTI ASME TURBO EXPO, Cincinnati, OH, May 24-27.

Walker, G.J. 1989. Transitional Flow on Axial Turbomachine Blading, AIAA Journal, no. 5, pp. 595-602.

Walker, G.J. and Gostelow, J.P. 1990. Effects of Adverse Pressure Gradients on the Nature and Length of Boundary Layer transition, Transactions of the ASME, vol. 112, pp. 196-205.

Wygnanski, I. 1981. The Effects of Reynolds Number and Pressure Gradient on the Transitional Spot in a Laminar Boundary Layer, Proc. Int. Conf. The Role of Coherent Structures in Modeling Turbulence and Mixing, Madrid, Springer-Verlag, Berlin, pp. 304-332. 

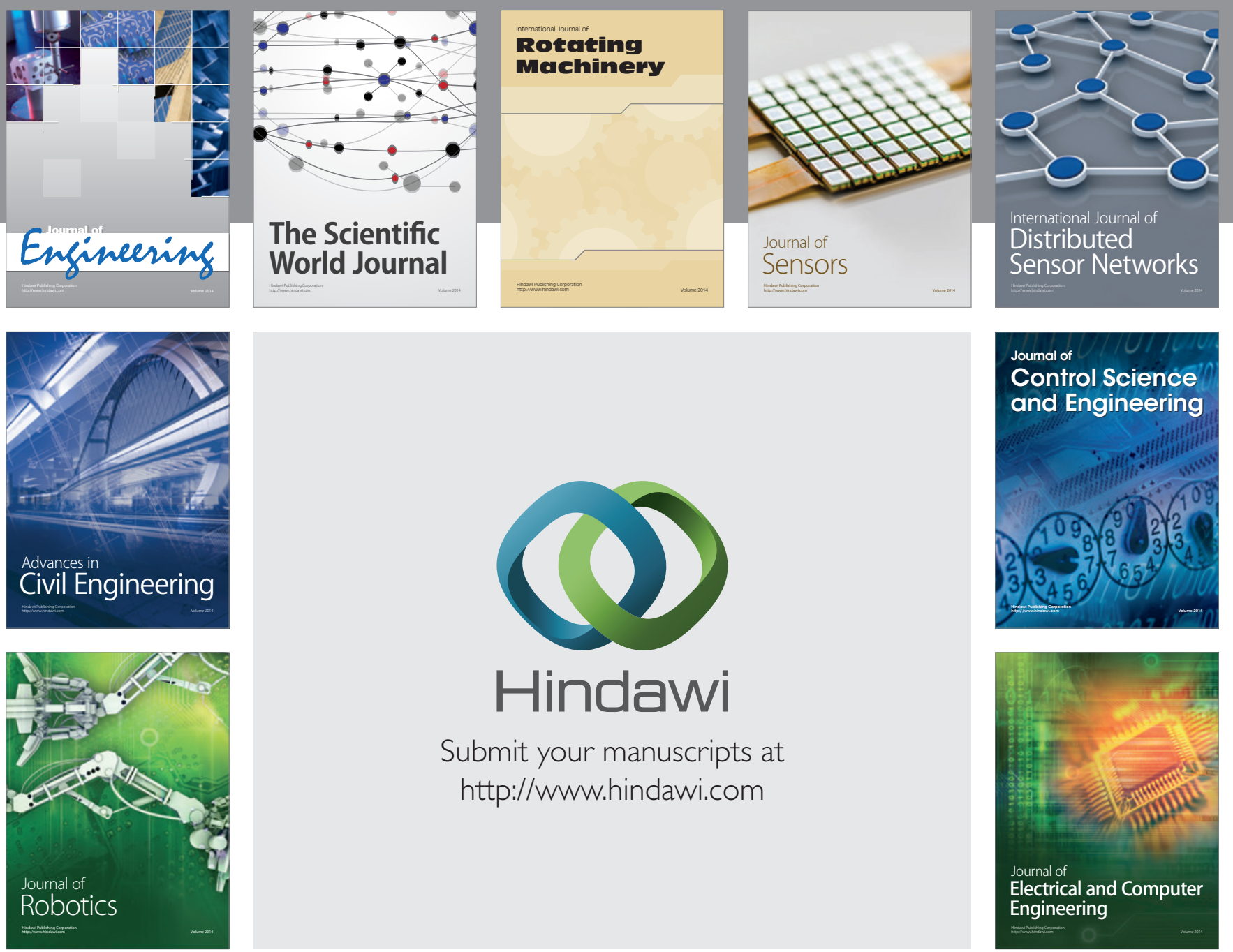

Submit your manuscripts at

http://www.hindawi.com
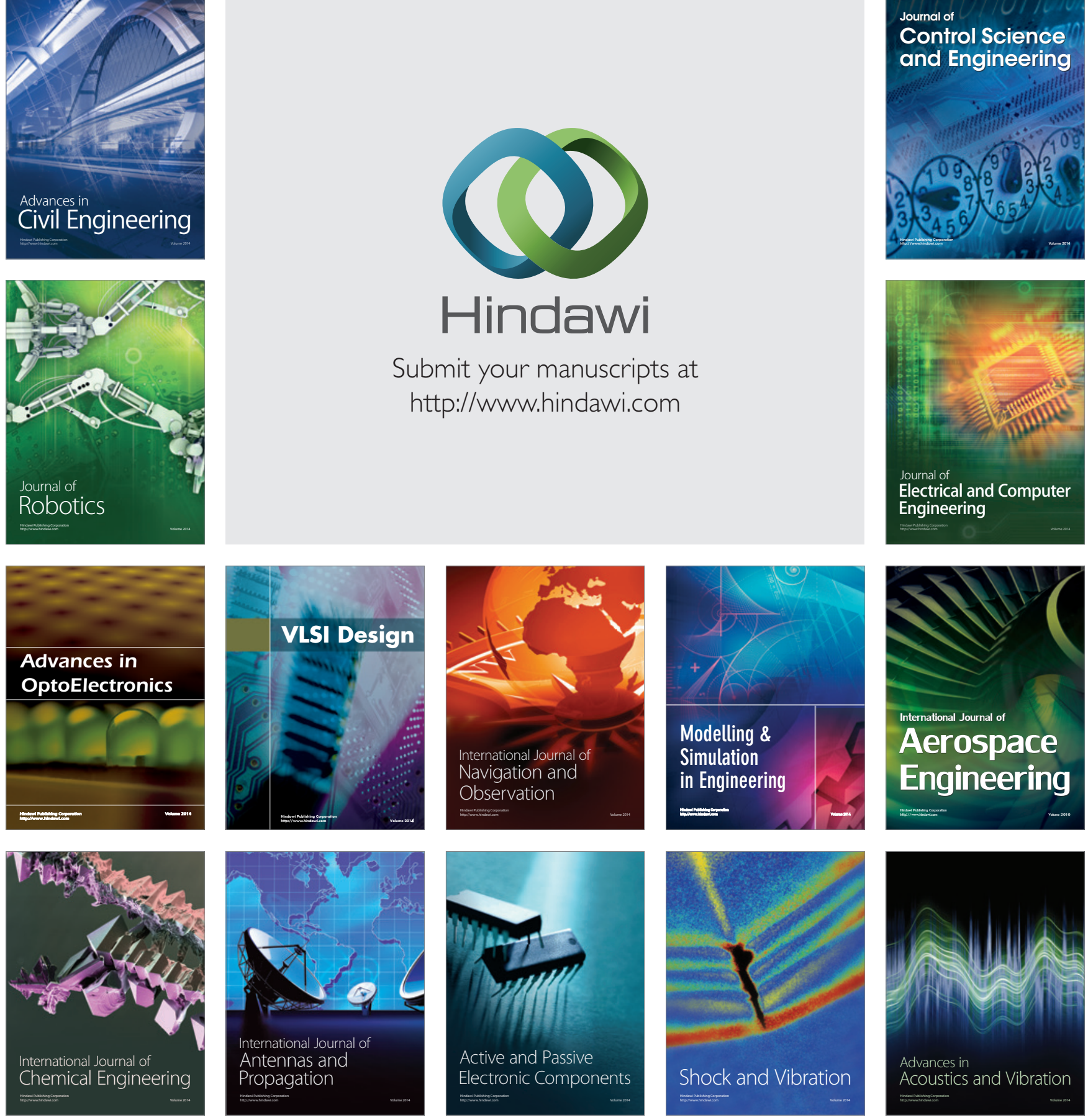